Särobs Sonacfer in Silbermanland an unb ift vermutlid burdi Saat nach einem Roggentrentment entftanben.

Die $\mathfrak{A n f n a b m e ~ e i n e r ~} \mathfrak{B r o b e f l a ̈ d e}$ son 0,32 ha ergab folgenbe Bahlen:

419 Riefern mit $31 \mathrm{~m}$ Mittelfübe, $37,6 \mathrm{~cm}$ mittlerem Durdjmeffer, $46,43 \mathrm{qm}$

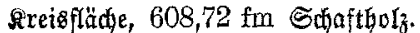

513 Fid)ten mit $23 \mathrm{~m}$ Mittelgobe, $23,9 \mathrm{~cm}$ mittlerem Durdimeffer, 20,24 qm

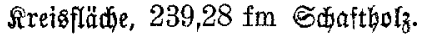

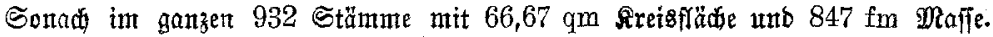

Eine Eleinere Brobeflädie von 0,116 ha ergab

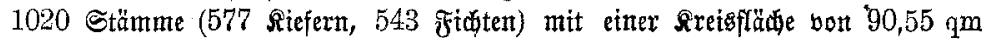
unb $1157 \mathrm{fm}$ Sajafthol

enblid) eine im bidfteften Teil bes Beftanbe aufgenommene, alferbing nur 0,049 ha groß̉e Probeflädje:

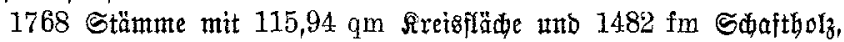

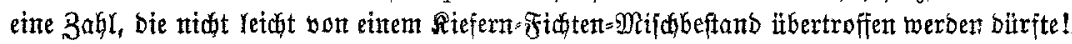

Der Gemeinbeworitand ber einjolägigen (semeinbe hat ben lobenswerten Bef

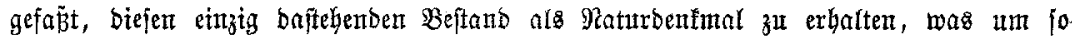

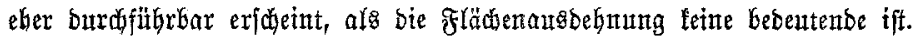

\title{
Oitafrifanilches Jedernholj.
}

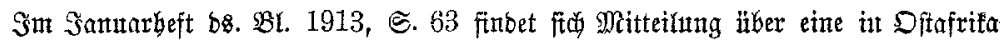

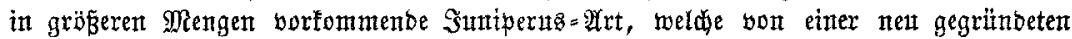

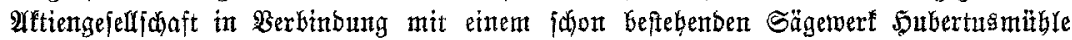

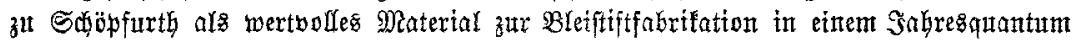
won runb $10000 \mathrm{ebm}$ gewonnent werben foll.

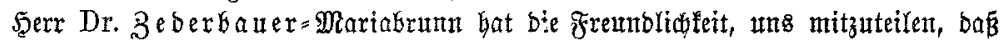

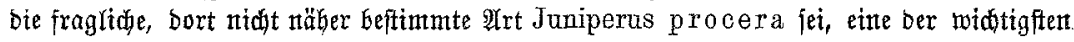

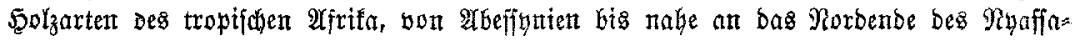

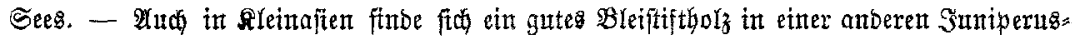
Art, nümlio in J. excelsa, bie ex felbit bort beobadet bafe; eq finbet bort Ber= wentintg als Batholy.

\section{Zeue Meḱl}

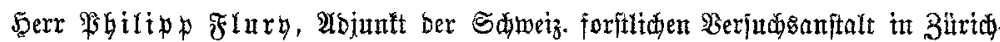

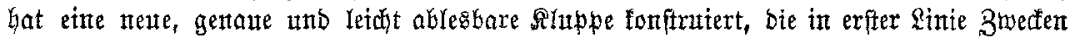

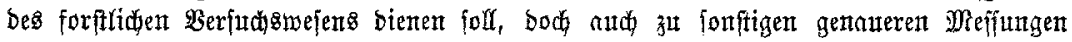

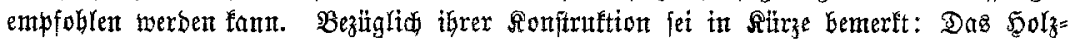
Iineal if mit Meffingioftenen armiert unt hat trapezförmigen Duerfontitt; bie Ieilung in Bentimeter und Miflimeter ift anf einer Belluloibplatte angebradit uno geftattet

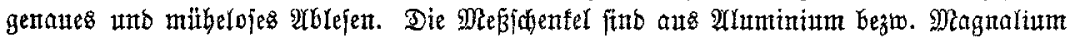

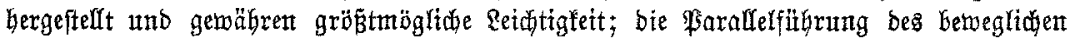

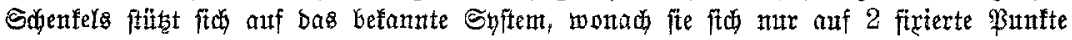

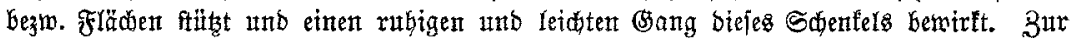
genauen Einftellung bient bann nod eine Surfterfdraube in Berbinbung mit einer Gegenfibraube, und ermöglidat bie Regulierung bei Wedjel bon trodnem unt feuditem Wetter. 